\title{
Laddered motivations of external whistleblowers: The truth about attributes, consequences and values.
}

\section{Introduction}

Understanding whistleblowers' motivators is of critical importance in terms of the theoretical and managerial implications. Most existing research has focused on investigating the individual factors that trigger the decision to blow the whistle: morality (Bouville, 2008; Street, 1995), justice (Miceli et al., 2012), public interest (Gobert \& Punch, 2000), loyalty (Westin, 1980; Larmer, 1992), fairness (Seifert et al., 2010; Waytz, Dungan, \& Young, 2013), and the seriousness of the wrongdoing (Ayers \& Kaplan, 2005; Miceli, Near, \& Schwenk, 1991). However, triggers are not motivations; motivation denotes the direction of the reaction to the trigger (Roberts, 2014). This direction is comprised by the attributes of whistleblowing (aspects or characteristics of the action taken to cope with a problem), consequences (expected outcomes of the action), and values (individual's principles as an internal reference for what is important).

Based on the view that whistleblowing is the result of a complex combination of various factors or multiple decisions, some researchers have applied theories or models to explain the motivations of those who are willing to blow the whistle. However, these studies are either conceptual and normative (Bouville, 2008; Gobert \& Punch, 2000; Larmer, 1992), make reductive assumptions about motivation in terms of 'altruism' or 'cost-benefit analysis' in order to build models (Dozier \& Miceli, 1985; Gundlach et al., 2003; Miceli et al., 2012; Seifert et al., 2010), or provide indirect inferences about motivation from studying whistleblower identity (Weiskopf \& Tobias-Miersch, 2016) or whistleblowing dilemma (Waytz et al., 2013). Whilst 
whistleblowers' motivations remain a topical issue in debates around whistleblowing legislation and policies (Braithwaite, 2013; Stikeleather, 2016; Yeoh, 2014), there remains a lack of empirical knowledge about the complexity and interactions of different aspects of what motivates people to blow the whistle. This study provides such knowledge from inductive research with an explicit focus on motivations of external whistleblowers. We used interview and survey data from 37 Korean whistleblowers to analyze different aspects of their motivations, using Means-End Chain (MEC) theory.

The purpose of this study was to explore the motivational structures of external whistleblowers involved in the decision to blow the whistle, in a more explicit, direct, and integrative way than previous research. Doing so makes both theoretical as well as practical contributions. Theoretically, we know of no other research that takes whistleblowers' motivations explicitly as its research object. Vandekerckhove (2006) finds that in the many definitions of whistleblowing, motivation is an implicit rather than an explicit factor. For example, Near and Miceli's (1985) standard definition of whistleblowing (cf. Brown et al., 2014) is based on a pro-social behavior model, and suggests whistleblowers do what they do "to effect action" (p. 4). Roberts (2014: 208) writes that this model "focuses upon the impact of the whistleblowing action rather than motivation". Hence, if we rely on the most widely used definition of whistleblowing for our knowledge about whistleblowers' motivations, we reduce motivation to consequences. Roberts further asserts (referring to Miceli et al., 2008) that "behavior does not have to be altruistic to be considered pro-social" (Roberts, 2014: 208) and concludes that "[for] researchers, it is a daunting task to separate out the messy contextual issues that bear upon identifying the motivations for whistleblowing" (Roberts, 2014: 228). Altruism and self-interest frequently overlap, e.g. disclosures about unsafe working conditions (Miceli et 
al, 2008) or whistleblowing about sexual harassment or bullying (Roberts, 2014). Hence, the extant whistleblowing literature conflates motivation with juxtaposing categories of values.

We further submit here that one's motivation to blow the whistle externally cannot be reduced to - yet is affected by - what the individual believes are salient aspects or characteristics of what they are doing (attributes): e.g. discharging one's duty, warning the public, getting a concern investigated, get someone to correct a wrong, etc. Our present study provides theoretical insight into how attributes, consequences, and values interact to form the motivational structure of whistleblowing. As such, this integrated approach constitutes our theoretical contribution to the whistleblowing literature. To this end we used Means-End Chain (MEC) theory, originally developed to uncover a hierarchically interconnected structure of motives that drive consumers to purchase a product or service (Gutman, 1982, 1997; Reynolds \& Gutman, 1988). The theory explains consumers' motivations to purchase through the hierarchical means-end relationships of attributes (A), consequences (C), and values (V), called means-end chains. Attributes at the lowest level are linked to the values as desired goals at the highest level through the consequences (Pieters, Baumgartner, \& Allen, 1995). Since the 1980s, the theory has been extensively applied with success to analyze the motivational structures for decision making in various areas such as organic food (Zanoli \& Naspetti, 2002), shopping (Wagner, 2007), residential development (Lundgren \& Lic, 2010), internet banking (Kuisma, Laukkanen, \& Hiltunen, 2007), and private equity financing (Morandin, Bergami, \& Bagozzi, 2006). The laddering technique is a main approach to elicit the means-end chains used to achieve a goal (Gutman, 1997; Pieters, Baumgartner, \& Allen, 1995). Researchers (e.g. Kuisma, Laukkanen, \& Hiltunen, 2007; Wagner, 2007) have suggested that MEC theory and the laddering technique are particularly useful for discovering the underlying motivational structure behind human 
behaviors. Given that whistleblowing is a behavior intended to achieve a specific purpose, MEC theory can be a research framework to analyze the motivation behind the decision to blow the whistle. Previous whistleblowing literature has considered attributes, consequences, and values separately, in either conceptual and normative papers, or by selective assumptions to develop a model. By using MEC theory, this paper contributes to the literature by providing insight into how attributes, consequences, and values interact. More precisely, our study finds that the motivation of external whistleblowers consists of a set of complex and multi-layered motivators. A whistleblower's motivation can be one of a limited number of combinations between attitudes, consequences, and values.

From a practical point of view, we believe the current study can make an important contribution to policy debates in Europe and elsewhere by demonstrating the hierarchical linkages among the preferred attributes of external whistleblowing, desired consequences, and end states (values). For example, whilst in the UK whistleblowing legislation was amended in 2013 replacing a 'good faith test' with the requirement that the whistleblower held a reasonable belief the disclosure was in the public interest, legislation passed in 2017 in France requires whistleblowers to act in 'good faith'. Furthermore, whilst NGOs like Transparency International and Whistleblowing International Network (WIN) lobby the European Commission for a Directive on whistleblower protection that does not put a whistleblower's motivation as a condition for protection, the cases brought before the European Court of Human Rights (which the European Commission cannot simply put aside when legislating) have consistently mentioned motivation of the whistleblower in its rulings. Finally, financial reward schemes for whistleblowers remain at the same time appealing and contested with regulators such as the FCA in the UK frequently reviewing their position on this. This study contributes to a deeper 
understanding of external whistleblowers' motivational structures by exploring the means-end chains that external whistleblowers consider in their disclosure of wrongdoing. The results of this study, which demonstrates the hierarchical linkages among the preferred attributes of external whistleblowing, desired consequences and end state, provide insights into how to design, implement, and review whistleblowing schemes for workers who report wrongdoing observed in their workplace.

Three questions were addressed in this study: what are the underlying attributes, consequences, and values of external whistleblowers when they blow the whistle? What motivational chains of A, C, and V play a dominant role in the decision to blow the whistle? And how are the three types of cognitive elements interlinked in the whistleblowers' means-end chains that connect their values to the decision to blow the whistle? The paper proceeds as follows. The next section provides a literature review of notions of motivation in the whistleblowing literature. We also include in the literature review a section on MEC theory. The section after that explains the methods of data collection and analysis used in this study. We then present the data analysis, before discussing the findings in a separate section. We conclude with a reflection on the implication and limitations of the study.

\section{Literature Review}

\section{Whistleblowing and Previous Studies on Its Motives}

The studies related to whistleblowing motivation can be divided into two broad groups in terms of approach. The overwhelming majority of the studies have focused on identifying the individual factors that facilitate whistleblowing, which include personal, situational, organizational, and contextual factors, as well as wrongdoing characteristics (e.g., Barnett, 1992; 
Mesmer-Magnus \& Viswesvaran, 2005; Vadera, Aguilera, \& Caza, 2009; Sims \& Keenan, 1998; Waytz, Dungan, \& Young, 2013). Miceli, Near, and Schwenk (1991) observed that some factors, such as the form and seriousness of the wrongdoing, the harm caused by the wrongdoing, morality, and the belief that the public is harmed by the wrongdoing, affect the decision to report the wrongdoing. Waytz, Dungan, and Young (2013) analyzed how fairness and loyalty increase or reduce willingness to report another person's unethical behavior to a third party. Based on a meta-analysis of 21 independent studies, Mesmer-Magnus and Viswesvaran (2005) examined the effects of the 193 correlates reported in the studies on whistleblowing intentions and actions in terms of their magnitude (how strongly related they were) and direction (positive or negative). They reported that personal and contextual factors and wrongdoing characteristics had closer relationships with the intent to blow the whistle than with actually blowing the whistle. This approach mostly focused on the impact of individual factors on the decision to report wrongdoing in "a single decision-point" or "the last step in the decision [process]" of whistleblowing (Blenkinsopp \& Edwards, 2008: 185-186; Jones, Spraakman, \& SanchezRodriguez, 2014: 648).

Another group of whistleblowing studies investigated cognitive factors that are involved in the decision to blow the whistle using a model or theory (e.g., Dozier \& Miceli, 1985; Ellis \& Arieli, 1999; Gundlach, Douglas, \& Martinko, 2003; Park \& Blenkinsopp, 2009). Dozier and Miceli (1985: 831-834) explained predictors of whistleblowing using a prosocial decision model that views whistleblowing as a result of a series of multiple decisions. Gundlach, Douglas, and Martinko (2003) proposed the social information processing model to show how whistleblowing decisions are motivated. This model consists of various factors predictive of whistleblowing, including employees' attributional process, perceptions of causes, consequences and judgments 
of responsibility for wrongdoing, and emotional reactions to perceived wrongdoing. Ellis and Arieli (1999) analyzed officers' intentions to report illegal or irregular activities in the Israeli Defense Forces using the reasoned action model (Ajzen \& Fishbein, 1980). According to their study, the model's two predictors (attitude toward reporting and subjective norm) had a significant effect on intention, although the effect of the subjective norm was much greater than that of the attitude. Park and Blenkinsopp (2009) tested the predictive validity of Ajzen's (1991) theory of planned behavior for whistleblowing intentions by investigating the extent to which three determinants (attitude, subjective norm, and perceived behavioral control) affected the reporting of wrongdoing. Based on the results, they reported that all three were significant in predicting intention for internal whistleblowing, but only subjective norm for that of external whistleblowing, showing that the theory has a high potential for explaining whistleblowing intentions, but that the effects differed depending on the type of whistleblowing.

Despite all of these efforts, little progress has been made to understand the drivers behind the decision to blow the whistle (Yeoh, 2014: 463). Knowledge about what kind of considerations whistleblowers actually make when going external is important when designing whistleblower programs. For such programs to be successful, they must be 'marketed' well, i.e. appeal to whistleblowers. Internal whistleblowing programs need to ensure that the internal process does not compel whistleblowers to make an external disclosure; whistleblowing programs of regulators or journalists need to deliver on what motivates external whistleblowing. Whistleblowing is the result of an employee's decision, which is directed toward achieving a specific goal. In MEC theory, the decision to blow the whistle is explained by a cognitive structure comprised of three types of motivators - attributes, consequences, and values - which are hierarchically interlinked. Attributes can be defined as the distinct aspects or characteristics 
of external whistleblowing, by which an employee thinks to bring about desired consequences and achieve the ultimate value of whistleblowing. Consequences are the positive outcomes the whistleblower expects from the external whistleblowing. Values are an individual's principles as an internal reference for what is important. A laddering technique is useful to uncover the hierarchical linkages among attributes, consequences, and values. Initially used in a context of marketing products to consumers (Gutman, 1982, 1997), the technique has often been adopted to find "the deep drivers of [...] decision-making" (Phillips \& Reynolds, 2009: 83; Reynolds \& Gutman, 1988). The application of MEC theory and the laddering technique help to develop an integrated understanding of how one comes to opt for external whistleblowing, beyond analyzing the impact of individual factors on the decision to blow the whistle.

\section{Means-End Chain Theory and Laddering}

Means-end chain theory is a conceptual framework based on the belief that consumers purchase a product or service not for its own sake, but for the benefits provided (Gutman, 1982, 1997). This theory posits that consumer decisions to purchase a product or service is a choice between means to attain a particular goal through consumption of the product or service. All human behaviors are directed by a connection among attributes, consequences, and values, called a means-end chain, in which each of them is interconnected and corresponds with a hierarchical goal sequence (Gutman, 1982, 1997; Reynolds \& Gutman, 1988): attributes as the features or aspects of a product or service, consequences as any expected results from consuming it, and values as desired end states. These three types of elements of a given product or service are classified into two sub-categories: concrete (tangible) and abstract (intangible) attributes; functional and psychological consequences; and terminal (ideal or long-term) and instrumental 
(serving as a means of achieving terminal goals) values (Gutman, 1982, 1997; Reynolds \& Gutman, 1988). Attributes are the lowest layer in the means-end chain, and they bring consequences that are linked to values, the highest level (Gutman, 1982, 1997). Consumers' decisions to purchase a product or service are ultimately guided by their values as preferred end states (Pieters, Baumgartner, \& Allen, 1995). MEC theory considers attributes, consequences, and values to be "the primary motivating and directing factor(s)" for customers to make a decision (Gutman, 1997: 547). A person might hold a value she/he wants to act on but will be able to decide on an action only if they also believe that value is linked with attributes and desirable consequences of a particular action. The theory has been employed as an important perspective for motivation studies in marketing and organizational management, among others (Kaciak \& Cullen, 2006; Rugg et al., 2002; Wagner, 2007). While means-end chain (MEC) theory was originally developed to explain consumers' behavior when choosing products or services that are available in the marketplace, numerous studies have shown that the theory can be suitable for a wide range of applications, including people's choices of “ideas, goals, or perceptions" as well as behaviors in various fields (Bagozzi \& Dabholkar, 2000, p. 535). For example, Bagozzi and Dabholkar (2000) applied the theory to explain the public's perceptions of President Clinton, and Bagozzi et al. (2003) used it to understand the motivations of volunteering to join the Italian army. Gengler, Mulvey, and Oglethorpe (1999) carried out a means-end analysis to explore the complexity of the motives behind why mothers choose to breastfeed. Using a means-end chain approach, Pieters, Baumgartner, and Allen (1995) explored the hierarchical structure of reasons for pursuing a course of action to participation in weight-loss programs while incorporating the concrete level of specific action plans and the more abstract level of values and motives. In that vein, we argue that the MEC laddering technique can be 
applicable to behaviors like whistleblowing.

The laddering technique is an in-depth interview method that has been extensively adopted to elicit sets of $\mathrm{A} \rightarrow \mathrm{C} \rightarrow \mathrm{V}$ linkages in MEC theory. In the laddering interview, researchers ask a series of probing questions about the reason for respondents' choice of action: why a particular attribute, consequence, or value is preferred to any other on the same level, and why it is so important to them. These 'why' questions are repeated to gain insight into the higher level in respondents' underlying motivations for their choices (Reynolds \& Gutman, 1988; Veludo-deOliveira, Ikeda, \& Campomar, 2006). Two different methods of generating A-C-V ladders have been commonly used in MEC studies (Kaciak, Cullen, \& Sagan, 2010; Phillips \& Reynolds, 2009): soft and hard. Soft laddering involves a qualitative in-depth interview, allowing respondents a more detailed response, while hard laddering is a quantitative intervieweradministered survey method in which laddering data is collected by a fixed set of closed questions. Soft laddering is effective for obtaining rich and personally meaningful information that is more appropriate to discover respondents' ladders (Kaciak, Cullen, \& Sagan, 2010). However, its application is "extremely time-consuming," resulting in high costs and complexity (Botschen, Thelen, \& Pieters, 1999; Russell et al., 2004: 279; Reynolds \& Gutman 1988; Valette-Florence \& Rapacchi, 1991). On the other hand, hard laddering is easier and less costly to administer because it uses a structured interview (Veludo-de-Oliveira, Ikeda, \& Campomar, 2006). Researchers (Botschen, Thelen, \& Pieters, 1999: 54-55; Grunert \& Grunert, 1995) have maintained that hard laddering gives similar results to soft laddering in terms of validity and reliability by keeping the interviewer from being biased toward the answers. For these reasons, some MEC studies (Botschen \& Thelen, 1998; Walker \& Olson, 1991) have employed hard laddering. 


\section{Methods}

\section{Subjects and Data Collection}

Data for analysis were collected from Korean external whistleblowers who gained much attention from the news media. Both soft laddering and hard laddering interviews were used. The laddering interviews were conducted as part of the research project of the Horuragi Foundation (2013), a civic group committed to protecting whistleblowers. Data were collected from May to August 2013. As the first step to build ladders, we conducted in-depth interviews, based on the method used by Valette-Florence and Rapacchi (1991) and Reynolds and Gutman's (1988) guidelines. Three trained interviewers (including one of the authors) with knowledge about the laddering technique firstly interviewed 13 external whistleblowers in a relaxed atmosphere for approximately one hour each. These interviews included asking them about what was on their minds at the time of blowing the whistle and inducing the respondents to progress from a lower level to a higher level in a ladder of abstraction until they could form a ladder of A-C-V. In the interviews, we asked a series of probing questions to elicit the ladders of attributes, consequences, and values of external whistleblowing. The attributes of whistleblowing were uncovered by questions: "What was the reason why you chose to let people know about the wrongdoing you observed in the workplace?"; "What attribute (specific aspects or features) of external whistleblowing did you think the most important when blowing the whistle?"; "What other features of the whistleblowing did you consider?"; "Why was that attribute more important to you than others?". Once the attributes were identified, the consequences as the second-level of means-end chains were asked: "Why was the attribute you just selected so important to you?"; "What other consequences did you expect from blowing the whistle?". As for values, we asked: "What was the ultimate goal of your whistleblowing?"; "Why did you think the goal you just selected was the most important to you at that time?". At each level of the means-end chain, we 
repeated a question to determine whether the respondents had any other response and to clarify what they meant by their response. During the laddering interviews, all responses were recorded. We conducted content analysis to extract the descriptors from the results of the interviews that met the means-end chains of MEC theory. Transcripts of the interview results were created to ladder the content analysis. Three researchers (a professor of whistleblowing, a former whistleblower, and a PhD student with a master's degree in MEC theory and laddering technique) independently classified all soft laddering interview data (consisting of words, phrases, or sentences) into A-C-V levels and then further broke down the responses into categories for each of the three levels of MEC theory, which were broad enough in meaning to retain the quality of the information. The three separately repeated this process for each of the 13 external whistleblowers. The results were recorded on a spreadsheet. They then jointly examined all the categories to: 1) merge categories by determining whether they were fit for laddering analysis regarding the origins of and differences in the exact meanings between the categories, and 2) reduce the number of categories based on the frequency of or emphasis on expressions of the words, phrases, or sentences used in the responses. They continued to collapse the A-C-V categories (obtained from soft laddering interviews) into fewer categories without losing any significant information through a subsequent examination. The reviews were stopped when the researchers believed that 5-10 had been reached, which was broad enough to capture the key concepts of A-C-V. In the final stage, the three agreed on approximately $85 \%$ of the categories and the assignments of the elements. They resolved the remaining inconsistencies through ongoing discussion of their personal differences while returning to the data and checking the meaning of elements (such as words, phrases, or sentences) of concern again until all A-C-V categories were coded. This procedure resulted in a hard laddering interview questionnaire that 
consisted of 24 questions: 5 for attributes, 10 for consequences, and 9 for values (see Table 1). INSERT TABLE 1 HERE

Table 1 shows all the attributes, consequences, and values of external whistleblowing that respondents considered both important and personally meaningful. A dictionary definition of an attribute is a characteristic, feature, property, or aspect of a person, behavior, or object, while a value is defined as a set of beliefs or ideas that guide people in their opinions or actions. For example, in this study, "duty" was identified as an attribute of whistleblowing because soft laddering interviews with external whistleblowers showed that blowing the whistle when wrongdoing is witnessed in the workplace was perceived as a behavior of civic duty. "Conscience" was selected as a terminal value or a sum of moral beliefs that whistleblowers think they can achieve by blowing the whistle because some whistleblowers answered that they blew the whistle to live a life of conscience; confirming this was the ultimate reason for their actions. Conscience can be construed as a kind of terminal moral value that needs to be maintained under any circumstances; it is a set of ideas that helps people distinguish between what is morally right or wrong. More broadly, it represents a standard of conformity for human behavior and an intrinsic but shared value of human beings that is closely linked to social norms, which reminds people of moral standards and encourages acting within them to avoid regret.

Based on these results of the soft laddering analysis, we developed a questionnaire for hard laddering (structured interviews that use a series of close-ended questions). As for the minimum sample size for a laddering study, Reynolds, Dethloff, and Westberg (2001: 96) suggested that laddering studies should include at least 20 respondents to conduct a conclusive analysis of the data. Coolen and Hoekstra (2001: 301) stated that, in most studies in which MEC theory is 
applied, the number of respondents for a laddering interview has been "at most 50 to 60 " to identify the important relations among attributes, consequences, and values. For this study, we invited 66 external whistleblowers (including 13 external whistleblowers who participated in the soft laddering interviews) to participate in the hard laddering interview. Most were identified through searching newspaper articles on the Internet, although some were introduced by members of whistleblowers' social networks and civic groups that are committed to whistleblower protection. These people had blown the whistle on wrongdoings, such as contaminated blood transfusions, construction corruption, false claims of travelling expenses, sexual violence against mentally retarded students, the illegal surveillance of civilians by the prime minister's office, etc.

Using an abbreviated hard laddering questionnaire (see Kaciak \& Cullen, 2006; Kaciak, Cullen, \& Sagan, 2010), we asked each of the participants to select one attribute of the whistleblowing, three consequences, and one value from the list of A, C, and V that was obtained from the soft laddering interviews. The literature shows considerable variety in the format of hard laddering. Walker and Olson (1991), who developed a paper-and-pencil version of the laddering interview, allowed respondents to identify up to four attributes and three reasons for each attribute. Considering that only a small portion of knowledge influences people's cognition and behavior at any given time, limiting the choices of respondents should not be of special concern. Out of many other possible formats, the primary reasons we asked respondents to select one attribute, three consequences, and one value from the list were as follows: (a) There is evidence showing that the quality of ladders is most likely to be confirmed when the respondent is asked to provide the most important attribute of a product or act, indicate up to three of the more important consequences of this attribute, and finally choose what is the ultimate value to 
him/her (Kaciak, Cullen \& Sagan, 2010; Kaciak \& Cullen, 2009); (b) during the soft laddering probes, we found that most respondents provided, on average, a series of three to four claims (consequences) when explaining one specific aspect of whistleblowing (attribute). We also realized that an attribute ultimately links to a small set of values through the consequences of whistleblowing.

Out of the invited 66 external whistleblowers, 42 agreed to take part in the hard laddering structured interviews. A compensation check of 50,000 Won (approximately USD 46) was offered for taking part in the interviews. A total of 37 external whistleblowers completed the laddering survey, as five refused to answer during the interviews because they felt reluctant to let a private matter be recorded.

\section{Data Analysis}

\section{Demographic Characteristics of the Sample}

Table 2 provides a short overview of the demographic characteristics of the sample of external whistleblowers who participated in the study.

\section{INSERT TABLE 2 HERE}

The respondents included 34 males and 3 females. Most of them were over forty and self or unemployed at the time of data collection. Among the respondents, $83.8 \%$ had a bachelor's degree or higher. 


\section{Frequency of Attributes, Consequences, and Values}

As a first step toward finding the matrix of relationships between the elements for means-end chains, frequency analysis of the elements was carried out. Table 3 presents the frequency of the attributes, consequences including overlapping responses, and values.

\section{INSERT TABLE 3 HERE}

Respondents reported "a4. Power to change" $(37.8 \%)$ to be the most important attribute of whistleblowing, followed by "a2. The warning of seriousness" (21.6\%), while "a3. The appeal for investigation" (5.4\%) was the least important. On the level of consequences, the functional consequence "c4. Correcting a wrong" $(27.6 \%)$ was considered the most desired by the respondents. The consequence "c2. Making those who cheated confess to their offenses" (23.8\%) was identified as the second most desired, while "c6. Informing people of the unjust situation I was in" $(1.9 \%)$ was the least desired of this level. With respect to values, the terminal value "v5. Truth" was the top priority $(35.1 \%)$ stated by the respondents. "v1. Challenges against abuses of power and money" and "v6. Public interest" followed v5, both making up $13.5 \%$ of the total responses. The instrumental value "v2. Right to know" and the terminal value "v7. Social justice" were chosen least frequently.

\section{The Implication Matrix}

The implication matrix as a next procedure of the laddering analysis was computed to produce a hierarchical value map and identify dominant means-end chains using the LadderUX program. The matrix represents the number of times each element connects to another on a ladder. Table 4 
presents an implication matrix that shows frequencies and direct and indirect relations among the attributes, consequences, and values. The matrix presents how many times each element is linked to others in two types of relations: direct and indirect. A direct relation indicates an unmediated relation between adjacent elements, whereas an indirect relation indicates a linkage between two elements when other elements interpose between them (Veludo-de-Oliveira et al., 2006). For example, a linkage like $\mathrm{A}-\mathrm{C}-\mathrm{V}$ includes two direct relations (A-C and $\mathrm{C}-\mathrm{V})$ and one indirect relation $(\mathrm{A}-\mathrm{V})$. The relations are presented in fractional form in the implication matrix, with a direct relation to the left and an indirect relation to the right. In the first row of Table 4, the cell made by the combination of a 1 and $c 2$ is $6 / 0$, which indicates that 6 respondents linked a1 directly to $\mathrm{c} 2$, and no respondent linked these elements indirectly. By contrast, the cell made by the combination of a1 and $v 5$ is $0 / 12$, which shows that 12 respondents indirectly linked a1 to v5 through other elements.

INSERT TABLE 4 HERE

As for the direct relation between attributes and consequences, the relation between "a4. Power to change" and "c4. Correcting a wrong" was the strongest $(n=10)$, followed by that $(n=9)$ of a4 and "c2. Making those who cheated confess to their offenses." In terms of the direct relation between consequences and values, that of $\mathrm{c} 2$ and "v5. Truth" was the strongest $(\mathrm{n}=11)$, followed by that $(n=7)$ of $c 4$ and $v 5$. The indirect relation between attributes and values showed that the relation of a4-v5 was the strongest $(n=17)$, followed by that $(n=12)$ of "a1. Public disclosure" and v5.

Hierarchical Value Map (HVM) 
A hierarchical value map (HVM) was constructed based on the results of the implication matrix. One way of producing the HVM is to include all associations between elements identified in the implication matrix. However, the most commonly used approach is to include only "significant relations" above cutoff scores (Veludo-de-Oliveira, Ikeda, \& Campomar, 2006: 635). In other words, each relation between two elements was compared to cutoff scores and included only when the relation was either greater than or at least equal to the relevant cutoff score. Otherwise, the relation was not included. In this way, we reduced the complexity of the results but increased the clarity of the HVM. The "cut-off level" is defined as "the minimum number of times two elements must be mentioned in the hierarchical value maps" (Skytte \& Bove, 2004: 332). Reynolds and Gutman (1988) suggested that researchers first try multiple cutoff levels to find the best informative solution. Pieters et al. (1995: 239) stated that a cut-off level is appropriate when $60-70 \%$ of all relations are represented in the maps. Using these criteria, this study selected a cut-off value of 2 , accounting for $64.08 \%$ (see Table 5).

\section{--------- INSERT TABLE 5 HERE -----------}

Although cutoff level 3 had the highest concentration index (the percentage of all links to cells), this level had the greatest possibility that the significant relations below the cutoff level would be ignored. Considering previous studies (Reynold \& Gutman, 1988; Pieters, Baumgartner, \& Allen, 1995), we chose cut-off level 2, which had ladders that accounted for the largest percentage of the total number of connections. At this level, the HVM showed 64.08\% of activated cells among the total, indicating that the map would represent almost two-thirds of all activated connections. Based on the data aggregated in the implication matrix, the hierarchical 
value map was drawn using the LadderUX program, which interconnects all significant chains above the cut-off level. Figure 1 shows the means-end chains that respondents used to make the decision to blow the whistle.

\section{INSERT FIGURE 1 HERE}

On the map, the sets the respondents' motivators are displayed based on the total number of relations. The chains with a greater number of relations refer to respondents' perceptual orientations as more important than those with a lower number of relations. The hierarchical associations among attributes, consequences, and values represent respondents' motivational structures of external disclosures, showing which attributes were chosen to gain particular consequences and which lead to the values as desired end states. Results showed the four main means-end chains: 1) "a4. Power to change" - "c4. Correcting a wrong" - "v5. Truth"; 2) "a4. Power to change" - "c2. Making those who cheated confess to their offenses" - "v5. Truth"; 3) “a2. The warning" - "c4. Correcting a wrong" - "v5. Truth"; and 4) "a2. The warning” - “c2. Making those who cheated confess to their offenses" - "v5. Truth." Although the motivation chains might seem to be varied and widely dispersed, the dominant chains started from two concrete attributes $(\mathrm{a} 4, \mathrm{a} 2)$, which were linked with two functional consequences $(\mathrm{c} 4, \mathrm{c} 2)$, resulting in one terminal value (v5). On the consequence level, respondents perceived two functional consequences "c4. Correcting a wrong" and "c2. Making those who cheated confess to their offenses" as much more important than other consequences, putting them in the center of respondents' hierarchical cognitive structures of whistleblowing. This result shows that the two consequences take a key motivating role in the decision to blow the whistle through connecting attributes and values. The strong motivation chains converged on "Truth" as a value, showing 
that the external exposures of wrongdoing are mostly triggered to attain "the truth." These results suggest that external whistleblowing is mostly motivated by the linkages among two concrete attributes (a4, a2), two functional consequences (c4, c2), and one terminal value (v5).

\section{Findings and Discussion}

The results of the laddering analysis provide empirical evidence about how motivation of external whistleblowing is structured as chains of attributes, consequences, and values. The important attributes of external whistleblowing that respondents articulated were power to change, warning of the seriousness of wrongdoing, appealing for an investigation, public disclosure, and duty as a member of society. The desired consequences of external whistleblowing that respondents found important were correcting a wrongdoing, making those who violated laws admit their offence, helping those who did wrong to be punished, regaining honor, reducing the time needed to correct the wrongdoing, and the last hope to solve the problem. The values articulated by respondents to be the ultimate goals of external whistleblowing were truth, public interest (public health and safety, environment, competition, right to know, and consumer interest), challenging abuse of power and money, conscience, loyalty (to the organization), human rights, fairness (procedural and substantive), and social justice (equal rights and opportunities).

The dominant means-end chain of external whistleblowers was found to include the linked sets

of two concrete attributes (power to change, and warning of serious wrongdoing), two functional consequences (correcting a wrongdoing, and making those who violated laws to admit their offence), and one terminal value (truth). This suggests that the decision to blow the whistle 
externally is largely driven by these cognitive elements: each of the two attributes were linked to both consequences, and truth as a preferred end state of external whistleblowing was put at the top of the chains. In order to understand these findings, it is important to note that external whistleblowing is most often preceded by internal whistleblowing (Rothschild \& Miethe, 1999; Vandekerckhove \& Phillips, 2017). Hence, whistleblowing is to be regarded as a protracted process rather than a one-off decision. Most whistleblowers initially raise concerns within their organization about violations that threaten the public interest, 'as they do not want to harm their employers' (Yeoh, 2014: 464). Further, Park et al. (2008) found that across cultures people prefer internal over external whistleblowing. However, after their reporting has been ignored for unjust reasons or they find themselves ostracized within the organization, whistleblowers might continue and disclose information about wrongdoing in the workplace to external parties. Our research presented in this article concerns the motivation of external whistleblowing; given the extant research it is safe to assume that our respondents' motivations were shaped by either their personal experience of an internal unsuccessful attempt to raise a concern and stop wrongdoing, or by the experience of seeing other unsuccessful internal whistleblowers in their workplace. In this sense, our findings for external whistleblowing do not necessarily suggest what the motivating attributes, consequences, and values are of internal whistleblowing. Weiskopf and Tobias-Miersch (2016), in their analysis of a whistleblowing case, showed how the whistleblower's reasoning about what he was doing changed throughout the process, from an initial belief that internal whistleblowing would bring change in the public interest by stopping the wrongdoing to a further attempt to bring about change by 'speaking truth' - Weiskopf and Tobias-Miersch (2016) use the concept of parrhesia. Our research provides a broader empirical base for characterizing the reasoning of 
whistleblowers who made external disclosures. More precisely, the external whistleblowing option - rather than the internal option - entails the attributes 'power to change' or 'warn the public' with the intended consequences 'correct the wrongdoing' or expose the 'bad guys'. But the value underpinning the attributes and consequences is 'truth', possibly because truth was precisely what was withheld in earlier unsuccessful internal reporting. Rothschild and Miethe (1999) and Weiskopf and Tobias-Miersch (2016) document how unsuccessful internal whistleblowing not only implies that the alleged wrongdoing continues but also that many untruths are generated, both about the voiced whistleblowing concern (e.g. the un-truth that no professional norms were breached) as well as about the whistleblower (e.g. un-truths about performance, professionalism and collegiality of the whistleblowing employee). Hence, extant scholarly knowledge about failures of internal whistleblowing helps to explain our findings about attributions, consequences, and values of external whistleblowing. In this sense, our research contributes to the literature by extending knowledge about external whistleblowing in line with extant knowledge about internal whistleblowing (Rotschild \& Miethe, 1999; Weiskopf \& Tobias-Miersch, 2016) and with extant quantitative research on whistleblowing as a protracted process (Vandekerckhove \& Phillips, 2017). This interpretation of our findings allows us to draw some broad recommendations for whistleblowing policies and programs. Internal whistleblowing programs ought to pay attention to avoid or undo generating untruths during the internal whistleblowing process, i.e. across the successive stages of raising, triage, investigating, possible corrective action, and communication with the whistleblower. Our research findings make it plausible that a failure to avoid or undo untruths might lead people to proceed to external whistleblowing. On the other hand, external whistleblowing programs (i.e. those initiated by regulators or journalists) might have greater 
success if they are constituted and operate around the notion of 'bringing truth to light'.

We wrote that our aim was to provide an integrated approach to the study of whistleblowing motivation by using MEC theory, given that the extant whistleblowing literature has at best looked at motivational factors in isolation. Our findings suggest MEC theory can do this, and thus connects what until now seemed disconnected streams of literature. At the attribution level, 'power to change' resonates with Near and Miceli's (1985) notion of "to effect action" in their pro-social model of whistleblowing; the literature on factors that trigger whistleblowing intentions and behavior resonates with our attribution of 'warning of the seriousness of wrongdoing'. At the consequence level, MEC theory integrates the two dimensions of successful whistleblowing (e.g. Vandekerckhove et al, 2014), namely whistleblowing that is both effective and safe: 'correcting a wrongdoing' (cf. Near \& Miceli, 1995) and 'making those who violated a law admit their offense' (cf. Smith \& Brown, 2008; cf. newspaper coverage of whistleblowers who finally get vindicated through the courts e.g. Wendy Addison after 11 years or more recently Luxleaks whistleblower Alain Deltour). At the end-state level in MEC theory, our finding that external whistleblowers are driven by one dominant value, namely truth, shows that previously mentioned literature at the attribution and consequence levels resonates with research using an identity/parrhesia lens (Kenny, 2017; Weiskopf \& Tobias-Miersch, 2016). Thus, our paper provides ground for seeing these various findings not as either contradictory or different theories of the same thing, i.e. motivation. Rather, different theoretical literatures have studied different aspects of motivation, i.e. attributes, consequences, or values. As such, MEC theory works well in offering a model that integrates research literature using various theoretical lenses on whistleblowers' motivation.

In discussing moral motivation across ethical theories, de Colle and Werhane (2008) note that 
generally ethical theories are presented according to a means-end rationality. Thus, Aristotle prescribes acting according to virtue (means) because doing so will make you happy as well (end), Kant prescribes acting according to the categorical imperative (means) because by doing so you will act according to the moral law within yourself (end), and Mill prescribes acting according to the Greatest Happiness Principle (means) because this will bring happiness, also for you (end). In this reasoning, the 'end' is what motivates us to do the 'means', and as such the ends rather than the means have moral value. Relying on Harsanyi's distinction between goaldirected rationality and criterion-satisfying rationality, de Colle and Werhane (2008) argue that whilst the goal-directed rationality - choosing the best means available for achieving a given end - has become the dominant assumption of economic theory, but that "in everyday life we use another model of rational behavior" (p. 755), one which entails an intrinsic coherence between the end and the means. In this account of rationality, the motivation to do something arises from becoming aware of that coherence. When using MEC theory to understand moral motivation, it might be useful to consider such a coherence-rationality. Thus, motivation for external whistleblowing arises from a cognitive coherence whistleblowers develop between means-andend, or between attribute, consequence, and value of an action. It is in this sense that we can understand motivation of whistleblowers to be multi-layered, or laddered. Our research suggests that within the cognitive means-end coherence that brings someone to do external whistleblowing, truth is the most important end-value. In this sense multiple laddered motivations may lead to external whistleblowing, however, any of those ladders is most likely to culminate in the value 'truth'.

Hannah et al (2011) distinguish between moral maturation and moral conation. Moral stage theories (e.g. Kohlberg) are theories of moral maturation, with each stage indicating increased 
complexity of moral sensitivity and moral judgement. Noting however that extant research demonstrates "relatively weak relationships between ethical judgments and ethical behaviors" (p. 674), Hannah et al (2011) call for more attention and work on moral conation, i.e. the capacity to generate motivation to act. This capacity includes moral ownership, moral efficacy, and moral courage. In our research, we used MEC theory to research moral conation rather than moral judgment. Thus, MEC theory could help to further research on actual whistleblowing. More precisely, MEC theory and the laddering technique could be used in future research to study the motivational differences between non-whistleblowing and whistleblowing observers of wrongdoing, or between internal whistleblowers who go on / who do not go on to external whistleblowing.

\section{Conclusions}

Three questions were addressed in this study: what are the underlying attributes (A), consequences (C), and values (V) of external whistleblowers when they blow the whistle? What motivational chains of A, C, and V play a dominant role in the decision to blow the whistle? And how are the three types of cognitive elements interlinked in the whistleblowers' means-end chains that connect their values to the decision to blow the whistle? Using soft and hard laddering techniques, results revealed that the motivation of external whistleblowers consisted of complex connections among attributes, consequences and values. However, motivational chains that play a dominant role in the decision to blow the whistle externally included the following cognitive factors: two attributes (power to change and the warning of the seriousness of wrongdoing), two consequences (correcting a wrongdoing and making those who violated laws admit their offense), and one value (truth). 
MEC theory integrates three types of cognitive aspects of motivation (attributes, consequences, values). Our findings suggest that the MEC theoretical model is able to integrate the extant research literature using various theoretical lenses on whistleblowers' motivation. Given that this extant literature is disperse and disconnected, MEC theory's integrative power is a contribution to the field.

However, we argued that although formulated as 'means-end-chain' it seems more appropriate to understand the links between the different cognitive aspects of moral motivation from the perspective of a coherence-rationality, rather than a goal-directed rationality.

Our study has several limitations. One limitation of this study is that the data is collected from Korean external whistleblowers, and as such their values might be influenced by their national culture. Hence it is necessary to reproduce this study in a different cultural setting. A second limitation concerns the data collection tools. Both survey and in-depth interviews are vulnerable to self-report or interest biases. Nevertheless, this study offers some valuable information on the hierarchical linkages among the cognitive factors (attributes, consequences, and values) involved in the decision to reporting wrongdoing to third parties.

A third limitation concerns the laddering technique. Previous research (e.g. Gengler \& Reynolds, 1995; Lin, 2002) reports some common problems with this method. Often respondents do not have "a ready answer" when asked questions about the A-C-V ladders, such as why a particular attribute or consequence was important to them or more important than others. Further, they do not fully articulate the meaningful differences or the associations between A-C-V because they have not previously thought of the reasons in terms of attributes, consequences, and personal values. Another problem in laddering interviews is that questions are too sensitive or too private. In this study, we did not experience these problems as seriously as reported in earlier 
studies. Most of our respondents were able to use relatively clear and compelling reasons. We believe that two measures were helpful in reducing the reported problems in this study: (a) Probing questions (for example, asking why an attribute (or consequence) was more important than others and "what does that really mean to you?") were repeated to force respondents to form an MEC in an A-C-V sequence; (b) three investigators (a professor of whistleblowing, a former whistleblower, and a PhD student with a master's degree in MEC theory and laddering technique) participated in classifying the content of the soft laddering interview data (consisting of either words, phrases, or sentences) for each of three levels of MEC theory (A-C-V) and resolving the remaining inconsistencies via ongoing discussion of their personal differences as well as returning to the data and checking the meaning of the elements of concern.

Finally, a fourth limitation of this study is that the accuracy of our findings might be affected by a recall bias. Almost $73 \%$ of our respondents had become an external whistleblower at least four years before participating in our research. This might explain why we had less problems than previously reported (cf. limitation four) during the interviews. Future research should aim to reduce the time between external whistleblowing and interview.

\section{References}

Ajzen, I. (1991). The theory of planned behavior. Organizational Behavior and Human decision Processes, 50(2), 179-211.

Ajzen, I., \& Fishbein, M. (1980). Understanding attitudes and predicting social behavior. Englewood Cliffs, NJ: Prentice Hall.

Ashton, J. (2015). When is whistleblowing in the public interest? Chesterton Global Ltd. \& Another v Nurmohamed leaves this question open. Industrial Law Journal, 44(3), 450-459. 
Ayers, S., \& Kaplan, S. E. (2005). Wrongdoing by consultants: An examination of employees' reporting intentions. Journal of Business Ethics, 57(2), 121-137.

Bagozzi, R. P., \& Dabholkar, P. A. (2000). Discursive psychology: An alternative conceptual foundation to means-end chain theory. Psychology and Marketing, 17(7), 535-586.

Bagozzi, R. P., Bergami, M., \& Leone, L. (2003). Hierarchical representation of motives in goal setting. Journal of Applied Psychology, 88(5), 915-945.

Barnett, T. (1992). A preliminary investigation of the relationship between selected organizational characteristics and external whistleblowing by employees. Journal of Business Ethics, 11(12), 949-959.

Blenkinsopp, J., \& Edwards, M. S. (2008). On not blowing the whistle: Quiescent silence as an emotion episode. In W. J. Zerbe, C. E. J. Hartel, \& N. M. Ashkanasy (Eds.), Research on emotion in organizations: Emotions, ethics and decision-making, volume 4 (pp. 181-206). Bradford, UK: Emerald.

Botschen, G., \& Thelen, E. M. (1998). Hard versus soft laddering: Implications for appropriate use. In I. Balderjahn, C. Mennicken, \& E. Vernette (Eds.), New developments and approaches in consumer behavior research (pp. 321-339). Stuttgart, GER: Schäffer-Poeschel.

Botschen, G., Thelen, E. M., \& Pieters, R. (1999). Using means-end structures for benefit segmentation: An application to services. European Journal of Marketing, 33(1-2), 38-58.

Bouville, M. (2008). Whistle-blowing and morality. Journal of Business Ethics, 81(3), 579-585.

Braithwaite, J. (2013). Flipping markets to virtue with qui tam and restorative justice. Accounting, Organizations and Society, 38(6-7), 458-468.

Brown, A. J., Lewis, D., Moberly, R. E., \& Vandekerckhove, W. (Eds.). (2014). International handbook on whistleblowing research. Cheltenham, UK: Edward Elgar. 
Coolen, H., \& Hoekstra, J. (2001). Values as determinants of preferences for housing attributes. Journal of Housing and the Built Environment, 16(3/4), 285-306.

De Colle, S., \& Werhane, P. (2008). Moral motivation across ethical theories: What can we learn for designing corporate ethics programs? Journal of Business Ethics, 81(4), 751-764.

Dozier, J. B., \& Miceli, M. P. (1985). Potential predictors of whistle-blowing: A prosocial behavior perspective. Academy of Management Review, 10(4), 823-836.

Ellis, S., \& Arieli, S. (1999). Predicting intentions to report administrative and disciplinary infractions: Applying the reasoned action model. Human Relations, 52(7), 947-967.

Gengler, C. E., Mulvey, M. S., \& Oglethorpe, J. E. (1999). A means-end analysis of mother's infant feeding choices. Journal of Public Policy \& Marketing, 18(2), 172-188.

Gengler, C., \& Reynolds, T. (1995). Consumer understanding and advertising strategy: Analysis and strategic translation of laddering data. Journal of Advertising Research, 35(4), 19-33.

Glazer, M. (1999). On the trail of courageous behavior. Sociological Inquiry, 69(2), 276-295.

Gobert, J., \& Punch, M. (2000). Whistleblowers, the public interest, and the Public Interest Disclosure Act 1998. Modern Law Review, 63(1), 25-54.

Gundlach, M. J., Douglas, S. C., \& Martinko, M. J. (2003). The decision to blow the whistle: A social information processing framework. Academy of Management Review, 28(1), 107-123.

Gutman, J. (1982). A means-end chain model based on consumer categorization processes. Journal of Marketing, 46(2), 60-72.

Gutman, J. (1997). Means-end chains as goal hierarchies. Psychology \& Marketing, 14(6), 545560. 
Hannah, S. T., Avolio, B. J., \& May, D. R. (2011). Moral maturation and moral conation: A capacity approach to explaining moral thought and action. Academy of Management Review, 36(4), 663-685.

Jones, J. C., Spraakman, G., \& Sanchez-Rodriguez, C. (2014). What's in it for me? An examination of accounting students' likelihood to report faculty misconduct. Journal of Business Ethics, 123(4), 645-667.

Kaciak, E. \& Cullen, C.W. (2006). Analysis of means-end chain data in marketing research. Journal of Targeting, Measurement \& Analysis for Marketing, 15(1), 12-20.

Kaciak, E. \& Cullen, C.W. (2009). A method of abbreviating a laddering survey. Journal of Targeting, Measurement \& Analysis for Marketing, 17(2), 105-113.

Kaciak, E., Cullen, C. W., \& Sagan, A. (2010). The quality of ladders generated by abbreviated hard laddering. Journal of Targeting, Measurement \& Analysis for Marketing, 18(3/4), 159166.

Kuisma, T., Laukkanen, T., \& Hiltunen, M. (2007). Mapping the reasons for resistance to internet banking: A means-end approach. International Journal of Information Management, $27(2), 75-85$.

Larmer, R. A. (1992). Whistleblowing and employee loyalty. Journal of Business Ethics, 11(2), $125-128$.

Lin, C. (2002). Attribute-consequence-value linkages: A new technique for understanding customer's product knowledge. Journal of Targeting Measurement and Analysis for Marketing, 10(4), 339-352.

Lundgren, B. A., \& Lic, T. (2010). Customers' perspectives on a residential development using the laddering method. Journal of Housing and the Built Environment, 25(1), 37-52. 
Mesmer-Magnus, J. R., \& Viswesvaran, C. (2005). Whistleblowing in organizations: An examination of correlates of whistleblowing intentions, actions, and retaliation. Journal of Business Ethics, 62(3), 277-297.

Miceli, M. P., \& Near, J. P. (1988). Individual and situational correlates of whistleblowing. Personnel Psychology, 41(2), 267-281.

Miceli, M. P., Near, J. P., \& Dworkin, T, M. (2008). Whistleblowing in organizations. New York, NY: Routledge.

Miceli, M. P., Near, J. P., \& Schwenk, C. R. (1991). Who blows the whistle and why? Industrial and Labor Relations Review, 45(1), 113-130.

Miceli, M. P., Near, J. P., Rehg, M. T., \& Van Scotter, J. R. (2012). Predicting employee reactions to perceived organizational wrongdoing: Demoralization, justice, proactive personality, and whistle-blowing. Human Relations, 65(8), 923-954.

Morandin, G., Bergami, M., \& Bagozzi, R. (2006). The hierarchical cognitive structure of entrepreneur motivation toward private equity financing. Venture Capital, 8(3), 253-271.

Near, J. P., \& Miceli, M. P. (1985). Organizational dissidence: The case of whistle-blowing. Journal of Business Ethics, 4(1), 1-16.

Near, J. P., \& Miceli, M. P. (1995). Effective whistleblowing. Academy of Management Review, 20(3), 679-708.

Park, H., \& Blenkinsopp, J. (2009). Whistleblowing as planned behavior - A survey of South Korean police officers. Journal of Business Ethics, 85(4), 545-556.

Phillips, J. M., \& Reynolds, T. J. (2009). A hard look at hard laddering: A comparison of studies examining the hierarchical structure of means-end theory. Qualitative Market Research: An International Journal, 12(1), 83-99. 
Pieters, R., Baumgartner, H., \& Allen, D. (1995). A means-end chain approach to consumer goal structures. International Journal of Research in Marketing, 12(3), 227-244.

Reynolds, T. J., \& Gutman, J. (1988). Laddering theory, method, analysis, and interpretation. Journal of Advertising Research, 28(1), 11-31.

Reynolds, T. J., Dethloff, C., \& Westberg, J. W. (2001). Means-end chains and laddering: An inventory of problems and an agenda for research. In T. C. Reynolds \& J. C. Olson (Eds.), Understanding consumer decision-making: The means-end approach to marketing and advertising strategy (pp. 91-118). Mahwah, NJ: Lawrence Erlbaum Associates.

Roberts, P. (2014). Motivations for whistleblowing: Personal, private and public interests. In A. J. Brown, D. Lewis, R. Moberly, \& W. Vandekerckhove (Eds.), International handbook on whistleblowing research (pp. 207-229). Cheltenham, UK: Edward Elgar.

Rothschild, J. \& Miethe, T. D. (1999). Whistle-blower disclosures and management retaliation: The battle to control information about organization corruption. Work and Occupations, 26(1), 107-128.

Rugg, G., Eva, M., Mahmood, A., Rehman, N., Andrews, S., \& Davies, S. (2002). Eliciting information about organizational culture via laddering. Information Systems Journal, 12(3), $215-229$.

Russell, C. G., Flight, I., Leppard, P., van Pabst, J. A. V., Syrette, J. A., \& Cox, D. N. (2004). A comparison of paper-and-pencil and computerized methods of "hard" laddering. Food Quality and Preference, 15(3), 279-291.

Seifert, D. L., Sweeney, J. T., Joireman, J., \&Thornton, J. M. (2010). The influence of organizational justice on accountant whistleblowing. Accounting, Organizations and Society, 35(7), 707-717. 
Sims, R. L., \& Keenan, J. P. (1998). Predictors of external whistleblowing: Organizational and intrapersonal variables. Journal of Business Ethics, 17(4), 411-421.

Skytte, H., \& Bove, K. (2004). The concept of retailer value: A means-end chain analysis. Agribusiness, 20(3), 323-345.

Smith, R., \& Brown, A. J. (2008). The good, the bad and the ugly: Whistleblowing outcomes. In A. J. Brown (Ed.), Whistleblowing in the Australian public sector (pp. 109-135). Canberra, AUS: ANU Press.

Stikeleather, B. R. (2016). When do employers benefit from offering workers a financial reward for reporting internal misconduct? Accounting, Organizations and Society, 52, 1-14.

Street, M. D. (1995). Cognitive moral development and organizational commitment: Two potential predictors of whistleblowing. Journal of Applied Business Research, 11(4), 104 110.

The Horuragi Foundation (2013). The report on whistleblowers' human rights violations. Seoul, South Korea.

Vadera, A. K., Aguilera, R. V., \& Caza, B. B. (2009). Making sense of whistle-blowing's antecedents: Learning from research on identity and ethics programs. Business Ethics Quarterly, 19(4), 553-586.

Valette-Florence, P., \& Rapacchi, B. (1991). Improvements in means-end chain analysis: Using graph theory and correspondence analysis. Journal of Advertising Research, 31(1), 30-45.

Vandekerckhove, W. (2006). Whistleblowing and organizational social responsibility. A global assessment. Aldershot, UK: Ashgate.

Vandekerckhove, W., \& Phillips, A. (2017). Whistleblowing as a protracted process. A study of UK whistleblower journeys. Journal of Business Ethics. doi 10.1007/s10551-017-3727-8 
Veludo-de-Oliveria, T. M., Ikeda, A. A., \& Campomar, M. C. (2006). Discussing laddering application by the means-end chain theory. The Qualitative Report, 11(4), 626-642.

Wagner, T. (2007). Shopping motivation revised: A means-end chain analytical perspective. International Journal of Retail \& Distribution Management, 35(7), 569-582.

Walker, B., \& Olson, J. (1991). Means-end chains: Connecting products with self. Journal of Business Research, 22(2), 111-118.

Waytz, A., Dungan, J., \& Young, L. (2013). The whistleblower's dilemma and the fairnessloyalty tradeoff. Journal of Experimental Social Psychology, 49(6), 1027-1033.

Weiskopf, R., \& Tobias-Miersch, Y. (2016). Whistleblowing, parrhesia and the contestation of truth in the workplace. Organization Studies, 37(11), 1621-1640.

Westin, A. F. (1980). Whistle-blowing: Loyalty and dissent in the corporation. New York, NY: McGraw Hill.

Yeoh, P. (2014). Whistleblowing: Motivations, corporate self-regulation, and the law. International Journal of Law \& Management, 56(6), 459-474.

Zanoli, R., \& Naspetti, S. (2002). Consumer motivations in the purchase of organic food: A means-end approach. British Food Journal, 104(8), 643-653. 